\title{
Thrombosis and spontaneous recanalization of a giant intracranial aneurysm: diagnostic and management pearls in a pediatric patient
}

\author{
Ali Kooshkabadi, MD, ${ }^{1}$ Brian Jankowitz, MD, ${ }^{1}$ Phillip A. Choi, BS, ${ }^{2}$ Gregory M. Weiner, MD, ${ }^{1}$ \\ and Stephanie Greene, MD' \\ 'Department of Neurosurgery, University of Pittsburgh Medical Center, and ${ }^{2}$ Department of Neurosurgery, University of
Pittsburgh School of Medicine, Pittsburgh, Pennsylvania
}

\begin{abstract}
The authors present the case of a boy who was successfully managed through the spontaneous thrombosis of a cavernous internal carotid artery (ICA) aneurysm, the subsequent occlusion of the ICA, its recanalization, and ultimate endovascular sacrifice, using only two angiograms because of the diagnostic capability of CT angiography. Spontaneous recanalization of the ICA following occlusion in the setting of a giant aneurysm has not been previously reported.
\end{abstract}

http://thejns.org/doi/abs/10.3171/2014.10.PEDS13588

KEY WORDS diagnostic technique; operative technique; vascular disorders

$\mathrm{P}$ EDIATRIC aneurysms pose unique diagnostic and management challenges. In this case, spontaneous recanalization of the internal carotid artery (ICA) following thrombosis of a giant aneurysm presented a unique clinical and radiological learning opportunity. Ultimately, $\mathrm{CT}$ angiography proved to be an invaluable tool in the management of this patient.

\section{Case Report}

History and Examination

A 12-year-old boy with no medical history presented to his pediatrician with 5 days of progressive headache and double vision. He was examined by an ophthalmologist, who noted a left sixth cranial nerve palsy and ordered MRI/MR angiography that showed a large mass adjacent to his left ICA that was suspicious for a cerebral aneurysm. The boy was sent to the Emergency Department at Children's Hospital of Pittsburgh, where a CT scan and CT angiography were performed, which showed no evidence of intracranial hemorrhage and the presence of a partially thrombosed giant left cavernous ICA aneurysm measuring $3.8 \times 3.7 \mathrm{~cm}$ (Fig. 1). The patient was admitted to the intensive care unit (ICU), and scheduled for an elective cerebral angiogram. On the morning of the angiogram, he developed worsening of his sixth cranial nerve palsy, and a new complete third cranial nerve palsy. An emergency head CT scan demonstrated no subarachnoid hemorrhage and increased hyperdensity within the lumen of the aneurysm. Following the CT scan, the patient underwent a cerebral angiogram that revealed spontaneous occlusion of the left ICA, with no filling past the petrous segment and no filling of the giant aneurysm. The patient supplied his left middle cerebral artery (MCA) and anterior cerebral artery (ACA) through a patent circle of Willis via a large left posterior communicating artery $(\mathrm{PCoA})$ and a patent anterior communicating artery. He was returned to the ICU after angiography, and immediately started on aspirin and a heparin drip with a goal partial thromboplastin time of 80 to 90 seconds. His neurological examination was unchanged in comparison with just prior to the angiogram (Fig. 2A and B).

The next day a routine $\mathrm{CT}$ angiogram verified the findings of the angiogram (Fig. 2C), with spontaneous thrombosis of the aneurysm and the left ICA from the skull base to the supraclinoid segment. There was reconstitution of flow at the supraclinoid segment with filling of the left MCA, ACA, and PCoA. That afternoon the patient developed slurring of his speech and right hemiparesis. Emergency MRI and MR perfusion showed multifocal restricted diffusion in the left $\mathrm{M}_{3}$ territory on both diffusionweighted imaging and on the perfusion scan, most con-

ABBREVIATIONS ACA = anterior cerebral artery; DSA = digital subtraction angiography; ICA = internal carotid artery; ICU = intensive care unit; $M C A=$ middle cerebral artery; $\mathrm{PCOA}=$ posterior communicating artery.

SUBMITTED November 17, 2013. ACCEPTED October 8, 2014.

INCLUDE WHEN CITING Published online November 7, 2014; DOI: 10.3171/2014.10.PEDS13588.

DISCLOSURE The authors report no conflict of interest concerning the materials or methods used in this study or the findings specified in this paper. 

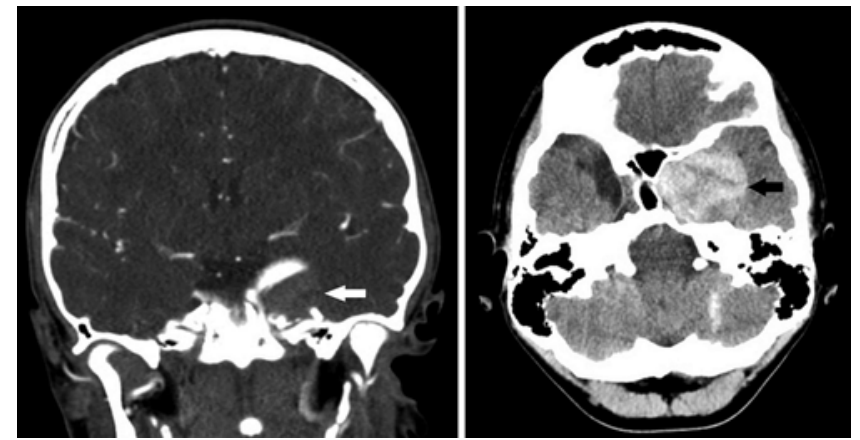

FIG. 1. Left: Initial coronal CT angiogram showing filling of the ICA and partial filling of the aneurysm (arrow). Right: Axial CT angiogram showing complete thrombosis of the aneurysm and ICA (arrow); the hyperdensity in the posterior fossa is an artifact.

sistent with embolic infarction and not hypoperfusion, as the infarcts were not simply in a watershed distribution (Fig. 3). An aggressive mean arterial pressure floor of 90 $\mathrm{mm} \mathrm{Hg}$ and anticoagulation with heparin and aspirin were continued. Over the next 2 weeks, the patient's right hemiparesis completely resolved. During the remainder of his hospitalization, 3 more CT angiograms were obtained to monitor for progression of the intracranial thrombosis as the heparin drip was weaned (Fig. 4). Repeat MR images

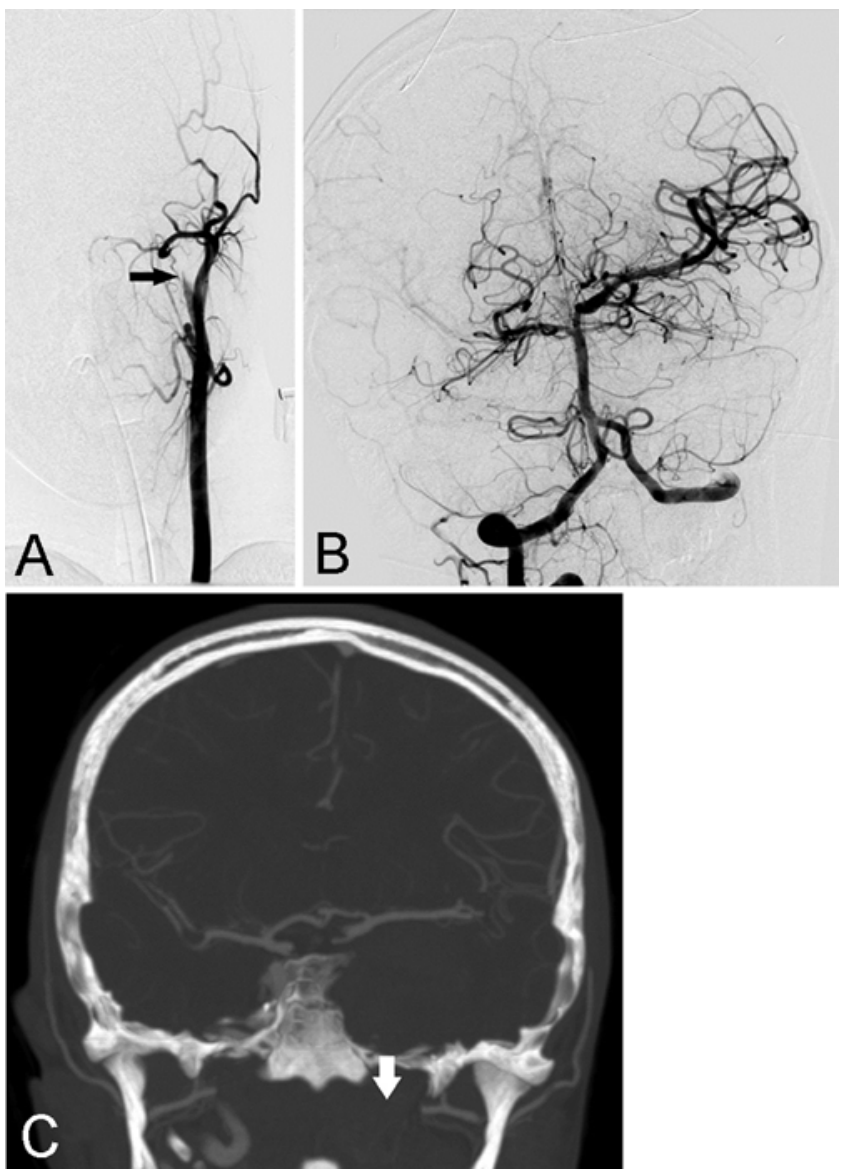

FIG. 2. A and B: Digital subtraction angiograms showing thrombosis of the ICA (A; arrow) and left MCA filling via the PCoA (B). C: Coronal CT angiogram obtained the following day verifying the findings of DSA and showing the lack of left ICA filling (arrow).
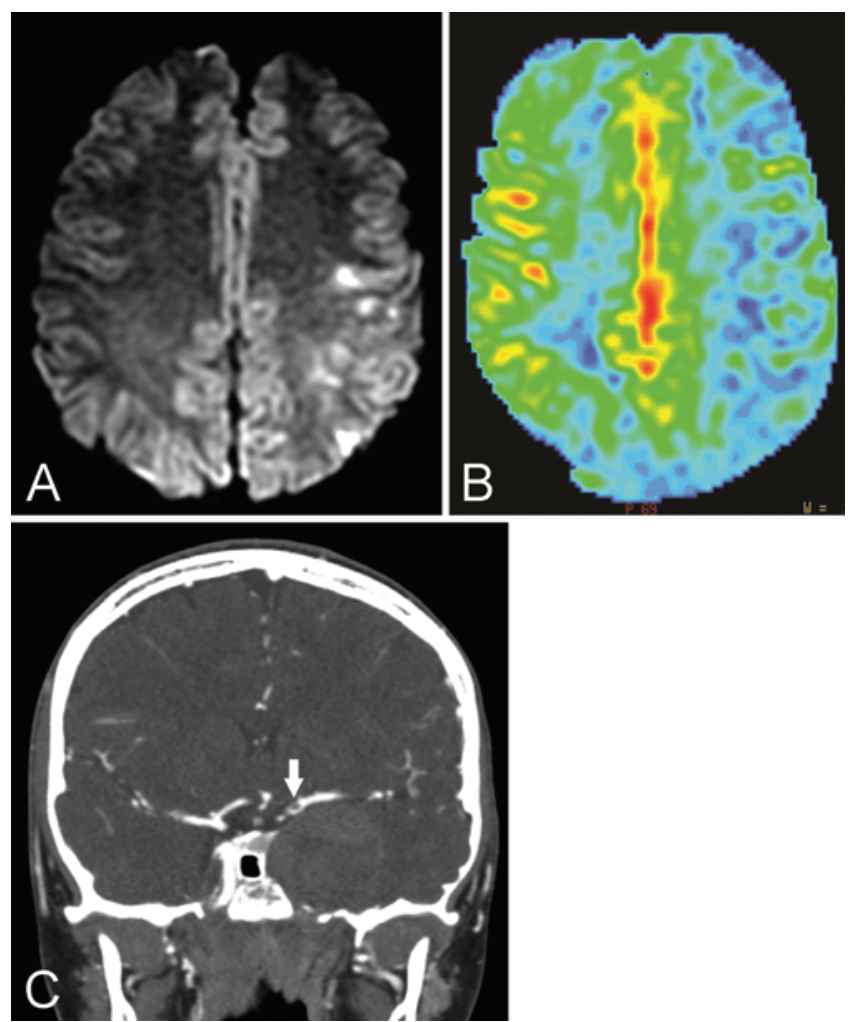

FIG. 3. A: Axial MR image obtained the same day as CT angiography showing diffusion-weighted imaging infarction (with apparent diffusion coefficient correlate not shown) after ICA occlusion. B: Axial MR perfusion image showing decreased cerebral blood flow in the left MCA territory. C: Follow-up coronal CT angiogram obtained 24 hours later showing progression of subocclusive thrombus to the ICA bifurcation (arrow). Figure is available in color online only.

during the heparin weaning indicated no new infarctions. The patient was discharged home on hospital Day 21. At discharge, the patient had complete left third and sixth cranial nerve palsies, but had no weakness on examination or other neurological deficits. His only discharge medication was $325 \mathrm{mg}$ of aspirin per day.

\section{Operation and Postoperative Course}

One month following his hospitalization, $\mathrm{CT}$ angiography revealed recanalization of the left ICA to the ophthalmic segment, and the patient was referred for endovascular balloon test occlusion and left ICA coil embolization (Fig. 5A and B). He underwent this procedure exactly 3 months after his initial presentation, and tolerated it without complication. The patient underwent genetic testing for connective tissue disorders, and was found to have a mutation in the MYH11 gene. He was diagnosed with a thoracic abdominal aneurysms and dissection spectrum disorder. Both his mother and sister were diagnosed with the same disorder after genetic testing. He underwent a normal echocardiogram, and was referred to the Cardiology Department for monitoring for the development of aortic dissection. Nine months after the ictus, he has regained full horizontal eye movements and some downward gaze. He has decreased ptosis, and nystagmus with downward 


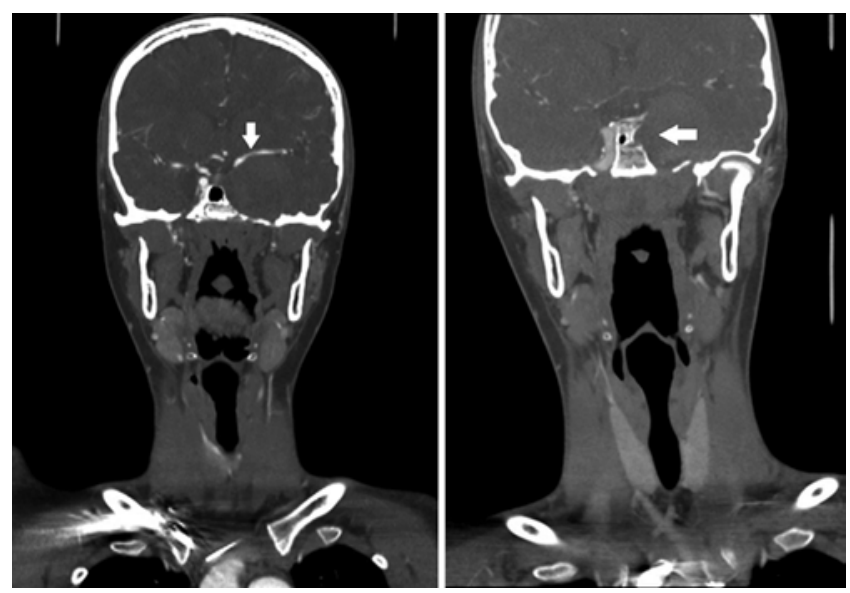

FIG. 4. Coronal CT angiograms showing regression of subocclusive thrombus after anticoagulation therapy (left; arrow) and stable ICA thrombosis 2 weeks after ictus (right; arrow).

gaze. The aneurysm is significantly smaller on repeat CT angiography (Fig. 5C).

\section{Discussion}

Pediatric cerebral aneurysms occur at a frequency between $0.17 \%$ to $6.8 \%$ among all patients treated for intracranial aneurysms. ${ }^{14,17-21,24}$ Estimates regarding the percentage of pediatric cerebral aneurysms that are giant (diameter $\geq 25 \mathrm{~mm}$ ) range from $14 \%$ to $54 \% .^{7-10}$ Pediatric cerebral aneurysms are most often found in the posterior circulation or the ICA bifurcation. ${ }^{22,26}$

Spontaneous thrombosis of giant intracranial aneurysms is a well-documented phenomenon, although spontaneous occlusion of the parent artery is uncommon.,.$^{1,2,11-14}$ The volume-to-neck ratio has been reported as a possible predictor of aneurysmal thrombosis, with values greater than 25 being favorable for thrombosis. ${ }^{3}$ In this case, the ratio was approximately 90 . Recanalization of the ICA following occlusion secondary to spontaneous thrombosis of a giant aneurysm has not been previously reported. Lee et al. reported a case of spontaneous recanalization of a completely thrombosed giant aneurysm of the posterior cerebral artery. ${ }^{15}$ The ICA thrombosis and embolic strokes that this patient suffered presented a challenging management dilemma. The progression of the thrombosis required frequent monitoring. In this case, the correlation between CT angiography and digital subtraction angiography (DSA) was excellent. CT angiography provided reliable and informative data regarding the thrombosed aneurysm, the extent of ICA thrombosis, and the distal blood flow provided by collateral circulation through the circle of Willis comparable to DSA with high sensitivity and specificity. ${ }^{5,27}$ The use of CT angiography enabled the patient to be monitored without invasive testing. The risk of embolic complications in children due to DSA is extremely low, 4,6,23,28 but the use of CTA for serial examinations decreases the risk of hypotensive strokes by obviating the need for general anesthesia. In patients younger than 16 years of age, general anesthesia is used at our institution to eliminate procedural pain and eliminate motion degrada-
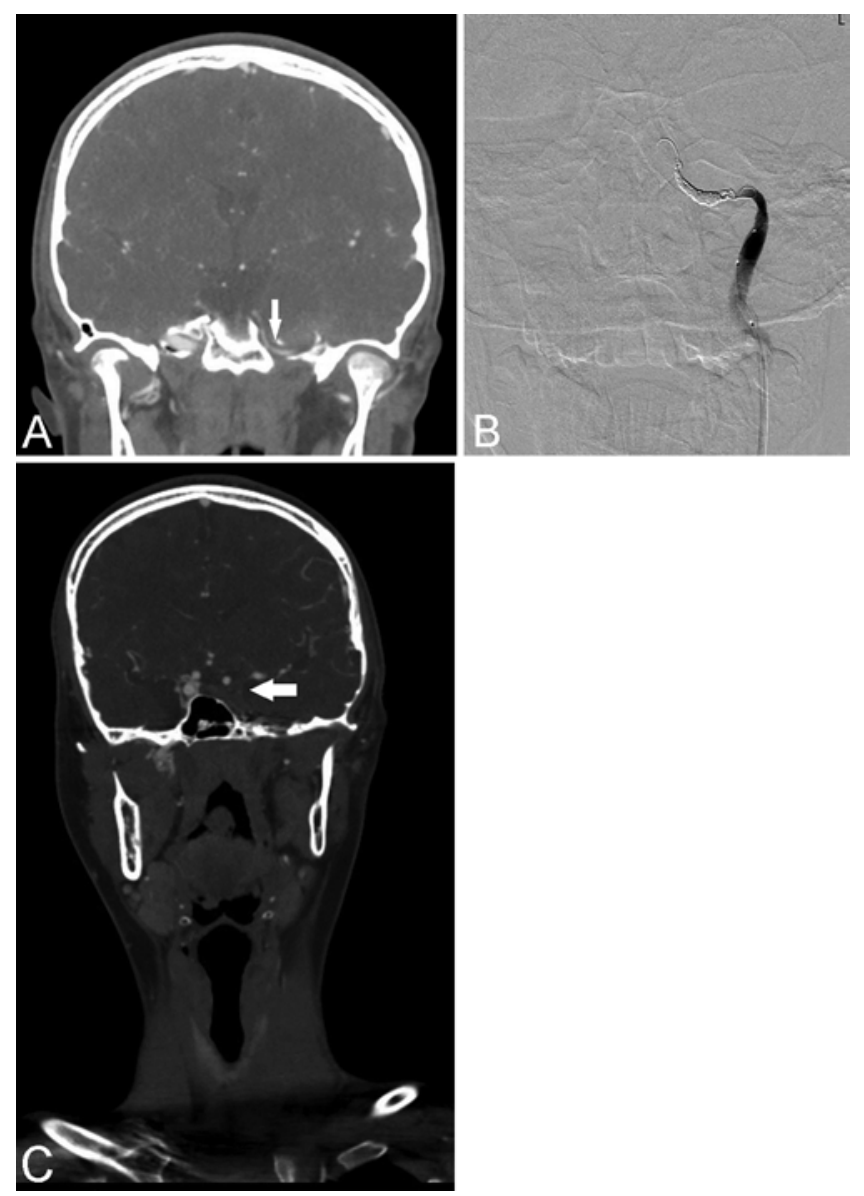

FIG. 5. A: Coronal CT angiogram showing recanalization of the ICA (arrow) noted at the 1-month follow-up examination. B: Angiogram showing endovascular sacrifice of the recanalized ICA as the final intervention. C: Nine-month follow-up coronal CT angiogram showing a decrease in aneurysm size and normalization of the position of the MCA (arrow).

tion of imaging. The effective dose for CT angiographic assessment of cerebral vessels is approximately one-fifth (17 mGy) the dose compared with DSA (75 mGy), and studies have shown that the estimated lifetime risk of developing radiation-related brain cancer relative to nonexposed children is increased by $2 \%-10 \%$ when the average absorbed dose to the brain is $17 \mathrm{mGy}$ (for CT angiography) and 163 mGy (for DSA). ${ }^{16,25}$ In this specific patient, who was at high risk of thoracic aortic dissection, the use of CT angiography allowed the risk of iatrogenic dissection to be minimized. CT angiography allowed for reliable noninvasive monitoring for recanalization as an outpatient, identified recanalization when it occurred, and led to the patient being referred for endovascular ICA sacrifice. Over a 3-month period of time the patient underwent a total of $5 \mathrm{CT}$ angiograms, 1 diagnostic angiogram, and 1 interventional cerebral angiogram.

\section{References}

1. Allison JW, Davis PC, Sato Y, James CA, Haque SS, Angtuaco EJ, et al: Intracranial aneurysms in infants and children. Pediatr Radiol 28:223-229, 1998 
2. Amacher AL, Drake CG, Ferguson GG: Posterior circulation aneurysms in young people. Neurosurgery 8:315-320, 1981

3. Black SP, German WJ: Observations on the relationship between the volume and the size of the orifice of experimental aneurysms. J Neurosurg 17:984-990, 1960

4. Burger IM, Murphy KJ, Jordan LC, Tamargo RJ, Gailloud P: Safety of cerebral digital subtraction angiography in children: complication rate analysis in 241 consecutive diagnostic angiograms. Stroke 37:2535-2539, 2006

5. Chappell ET, Moure FC, Good MC: Comparison of computed tomographic angiography with digital subtraction angiography in the diagnosis of cerebral aneurysms: a metaanalysis. Neurosurgery 52:624-631, 2003

6. Fung E, Ganesan V, Cox TS, Chong WK, Saunders DE: Complication rates of diagnostic cerebral arteriography in children. Pediatr Radiol 35:1174-1177, 2005

7. Gautier JC, Awada A, Majdalani A: Ophthalmoplegia with contralateral hemiplegia. Occlusion of the internal carotid artery due to thrombosis of an intracavernous aneurysm. Stroke 17:1321-1322, 1986

8. Gerber S, Dormont D, Sahel M, Grob R, Foncin JF, Marsault $\mathrm{C}$ : Complete spontaneous thrombosis of a giant intracranial aneurysm. Neuroradiology 36:316-317, 1994

9. Gerosa M, Licata C, Fiore DL, Iraci G: Intracranial aneurysms of childhood. Childs Brain 6:295-302, 1980

10. Iplikcioglu AC, Dinc C, Bek S, Bikmaz K: Spontaneous thrombosis and resorption of a giant fusiform A2 aneurysm. Case illustration. J Neurosurg 105:788, 2006

11. Kasliwal MK, Suri A, Sai Kiran NA, Sharma BS: Spontaneous thrombosis of giant cavernous internal carotid artery aneurysm in a neonate. Case report and review of the literature. Pediatr Neurosurg 44:329-332, 2008

12. Krapf H, Schöning M, Petersen D, Küker W: Complete asymptomatic thrombosis and resorption of a congenital giant intracranial aneurysm. Case report. J Neurosurg 97:184-189, 2002

13. Kurokawa R, Kuroshima Y, Yoshida K, Kawase T: Spontaneous thrombosis of intracavernous internal carotid artery aneurysm and parent artery occlusion in patients with positive balloon test occlusion - two case reports. Neurol Med Chir (Tokyo) 41:436-441, 2001

14. Lasjaunias P, Wuppalapati S, Alvarez H, Rodesch G, Ozanne A: Intracranial aneurysms in children aged under 15 years: review of 59 consecutive children with 75 aneurysms. Childs Nerv Syst 21:437-450, 2005

15. Lee KC, Joo JY, Lee KS, Shin YS: Recanalization of completely thrombosed giant aneurysm: case report. Surg Neurol 51:94-98, 1999

16. Manninen AL, Isokangas JM, Karttunen A, Siniluoto T, Nieminen MT: A comparison of radiation exposure between diagnostic CTA and DSA examinations of cerebral and cervicocerebral vessels. AJNR Am J Neuroradiol 33:20382042, 2012
17. Meyer FB, Sundt TM Jr, Fode NC, Morgan MK, Forbes GS, Mellinger JF: Cerebral aneurysms in childhood and adolescence. J Neurosurg 70:420-425, 1989

18. Norris JS, Wallace MC: Pediatric intracranial aneurysms. Neurosurg Clin N Am 9:557-563, 1998

19. Ostergaard JR: Aetiology of intracranial saccular aneurysms in childhood. Br J Neurosurg 5:575-580, 1991

20. Ostergaard JR, Voldby B: Intracranial arterial aneurysms in children and adolescents. J Neurosurg 58:832-837, 1983

21. Patel AN, Richardson AE: Ruptured intracranial aneurysms in the first two decades of life. A study of 58 patients. J Neurosurg 35:571-576, 1971

22. Rinkel GJ: Natural history, epidemiology and screening of unruptured intracranial aneurysms. Rev Neurol (Paris) 164:781-786, 2008

23. Robertson RL, Chavali RV, Robson CD, Barnes PD, Eldredge EA, Burrows PE, et al: Neurologic complications of cerebral angiography in childhood moyamoya syndrome. Pediatr Radiol 28:824-829, 1998

24. Sedzimir CB, Robinson J: Intracranial hemorrhage in children and adolescents. J Neurosurg 38:269-281, 1973

25. Thierry-Chef I, Simon SL, Miller DL: Radiation dose and cancer risk among pediatric patients undergoing interventional neuroradiology procedures. Pediatr Radiol 36 (Suppl 2):159-162, 2006

26. Vasconcellos LP, Flores JA, Conti ML, Veiga JC, Lancellotti CL: Spontaneous thrombosis of internal carotid artery: a natural history of giant carotid cavernous aneurysms. Arq Neuropsiquiatr 67 (2A):278-283, 2009

27. Wintermark M, Uske A, Chalaron M, Regli L, Maeder P, Meuli R, et al: Multislice computerized tomography angiography in the evaluation of intracranial aneurysms: a comparison with intraarterial digital subtraction angiography. J Neurosurg 98:828-836, 2003

28. Wolfe TJ, Hussain SI, Lynch JR, Fitzsimmons BF, Zaidat OO: Pediatric cerebral angiography: analysis of utilization and findings. Pediatr Neurol 40:98-101, 2009

\section{Author Contributions}

Conception and design: Kooshkabadi, Jankowitz, Choi, Greene. Acquisition of data: all authors. Analysis and interpretation of data: Kooshkabadi, Jankowitz, Choi, Greene. Drafting the article: all authors. Critically revising the article: all authors. Reviewed submitted version of manuscript: Kooshkabadi, Jankowitz, Weiner, Greene. Approved the final version of the manuscript on behalf of all authors: Kooshkabadi. Study supervision: Greene.

\section{Correspondence}

Ali Kooshkabadi, University of Pittsburgh Medical Center, 200 Lothrop St., Pittsburgh, PA 15213. email: kooshster@gmail.com. 